\title{
Klasifikasi Kemurnian Daging Sapi Berbasis Electronic Nose dengan Metode Principal Component Analysis
}

\author{
Fachri Rosyad*1, Danang Lelono ${ }^{2}$ \\ ${ }^{1}$ Program Studi Elektronika dan Instrumentasi, JIKE, FMIPA, UGM, Yogyakarta \\ ${ }^{2}$ Jurusan Ilmu Komputer dan Elektronika, FMIPA UGM, Yogyakarta \\ e-mail: *1 fahri.rosyad@gmail.com, ${ }^{2}$ danang@ugm.ac.id
}

\begin{abstract}
Abstrak
Daging merupakan bahan makanan yang dikonsumsi secara luas, sehingga dibutuhkan standar kualitas tertentu agar dapat aman dikonsumsi dan tidak merugikan konsumen. Standar tersebut diantaranya adalah kesegaran dan kemurnian. Dalam praktek jual beli daging ditemukan adanya kasus pencampuran daging sapi dengan daging babi sehingga dapat merugikan konsumen. Untuk mengetahui kemurnian daging sapi tersebut dibutuhkan pengujian dengan menggunakan tes aroma berbasis electronic nose.

Sampel daging sapi campuran dibuat dengan variasi kandungan daging babi sebesar 20\%, 40\%, 60\%, dan 80\% dari total massa sampel, dengan massa sampel adalah 20 gram. Pengambilan data selama 10 hari dilakukan dengan proses sensing dan flushing masingmasing selama 180 detik dengan pengulangan sebanyak 6 kali per hari. Pengolahan data dilakukan dalam beberapa tahap yang meliputi prapemrosesan sinyal dengan manipulasi baseline, ekstraksi ciri dengan menghitung luas kurva sinyal menggunakan pendekatan integral aturan trapesium, dan analisis multivariat menggunakan Principal Component Analysis (PCA).

Hasil persentase variansi kumulatif dua komponen utama pada pengujian klasifikasi antara daging sapi dengan daging babi adalah sebesar 99,9\%, sedangkan pada pengujian klasifikasi antara daging sapi murni dengan daging sapi campuran adalah sebesar 99,6\%. Dengan demikian, electronic nose dapat membedakan antara daging sapi murni dengan daging sapi campuran.
\end{abstract}

Kata kunci-Electronic nose, sensor gas metal oksida, klasifikasi, kemurnian daging, Principal Component Analysis.

\begin{abstract}
Meat is a widely consumed food, therefore it requires certain quality standards to be safe to consumed and does not harm the consumers. Several of those standards including meat freshness and meat purity. Recently it has been found some cases of pork adulteration in beef which consequently could harm the consumers. In order to examine the purity of beef, it required test method based on odor characteristics by using electronic nose.

Adulterated beef samples were prepared with pork content within samples varied by $20 \%, 40 \%, 60 \%$, and $80 \%$ of total sample mass where the sample mass is 20 grams. The 10 days data collecting consists of sensing and flushing cycles for 180 seconds each cycles, with 6 times process repeating over 1 day. Data processing was carried out in several stages which including signal preprocessing based on baseline manipulation, feature extraction by calculating the area of the response signal curve by using trapezoidal rule of integral approximation, and multivariate analysis using PCA.

Cumulative percentage of variance of two principal components of beef and pork classification test yields at $99.9 \%$ of total variance, and classification test between pure beef and adulterated beef resulting in $99.6 \%$ of total variance. Therefore, it can be concluded that electronic nose can classify between pure beef and adulterated beef.
\end{abstract}

Keywords - Electronic nose, metal-oxide gas sensor, classification, meat purity, Principal Component Analysis.

Received April 10 ${ }^{\text {th }}, 2015$; Revised April 13 ${ }^{\text {th }}, 2016$; Accepted April 29 $9^{\text {th }}, 2016$ 


\section{PENDAHULUAN}

$\mathrm{D}$ alam kegiatan jual beli daging ditemukan adanya praktek pencampuran suatu jenis daging dengan daging jenis yang lain yang lebih murah atau yang kualitasnya lebih rendah agar didapatkan keuntungan yang lebih besar dari segi ekonomi bagi penjual [1]. Contoh dari praktek pencampuran daging ini adalah pencampuran daging sapi dengan daging babi. Tindakan pencampuran daging ini apabila dilakukan tanpa izin dari pihak berwenang atau tanpa memberikan keterangan yang jelas mengenai produk yang dijual pada konsumen maka dapat merugikan konsumen.

Berbagai metode ilmiah telah dikembangkan untuk mengidentifikasi pencampuran daging, diantaranya adalah metode kromatografis dan spektroskopis yaitu Gas Chromatograpgy (GC) dan Mass Spectrometer (MS), High Performance Liquid Chromatography (HPLC), Nuclear Magnetic Resonance (NMR) Spectroscopy, dan Fourier Transform Infrared (FTIR) Spectroscopy. Metode-metode tersebut adalah metode yang paling spesifik dan sensitif untuk identifikasi, namun membutuhkan peralatan laboratorium yang mahal dan tenaga ahli yang berpengalaman sehingga membuat metode tersebut penggunaannya terbatas [1].

Kebutuhan akan adanya solusi untuk melakukan pengujian sampel bahan makanan yang dalam hal ini adalah daging dengan menggunakan instrumen dan metode yang lebih praktis dengan analisis data yang lebih cepat dan biaya yang lebih murah namun dengan hasil yang tetap dapat diandalkan mengarahkan para peneliti untuk mengembangkan electronic nose. Electronic nose adalah instrumen untuk melakukan uji sampel berdasarkan aroma sampel tersebut untuk keperluan identifikasi dan klasifikasi. Electronic nose tersusun atas larik sensor gas metal oxide yang mempunyai kelebihan dibandingkan dengan metode lain untuk menganalisis aroma makanan yaitu dalam hal sampel yang dibutuhkan lebih sedikit, analisis yang lebih cepat, kepraktisan penggunaan, dan biaya yang lebih murah [1]. Akhir-akhir ini electronic nose menjadi semakin populer sebagai metode analisis makanan non destructive. Dalam bidang analisis makanan, terdapat lima kategori utama dimana electronic nose dapat digunakan dalam bidang pengawasan makanan yaitu monitoring proses, pemeriksaan kadaluwarsa, evaluasi kesegaran, uji kemurnian dan studi quality control makanan lainnya. Sementara itu para peneliti telah melaporkan bahwa telah didapat hasil yang baik pada penggunaan Principal Component Analysis sebagai metode analisis data Electronic Nose untuk keperluan uji deteksi dan klasifikasi sampel [2]. Oleh karena itu maka pada penelitian ini dilakukan uji klasifikasi daging sapi murni dengan daging sapi campuran menggunakan electronic nose dengan metode analisis data Principal Component Analysis.

\section{METODE PENELITIAN}

\subsection{Bahan}

Bahan yang digunakan dalam penelitian ini adalah daging sapi segar dan daging babi segar.

\subsection{Peralatan}

Sistem electronic nose (e-nose) yang digunakan pada penelitian ini adalah e-nose yang dikembangkan oleh Iswanto pada tahun 2014 yang merupakan e-nose berbasis sensor gas metal oxide. Sensor gas yang digunakan berjumlah 5 sensor dengan jenis yang berbeda dimana masing-masing sensor mempunyai kepekaan terhadap senyawa gas tertentu. Secara umum sistem e-nose ini terdiri dari empat bagian utama yaitu sensing element, pengondisi sinyal dan konversi analog ke digital, processing dan graphical user interface [3]. Diagram blok dari sistem e-nose yang digunakan dalam penelitian ini ditunjukkan pada Gambar 1.

IJEIS Vol. 6, No. 1, April 2016 : $47-58$ 


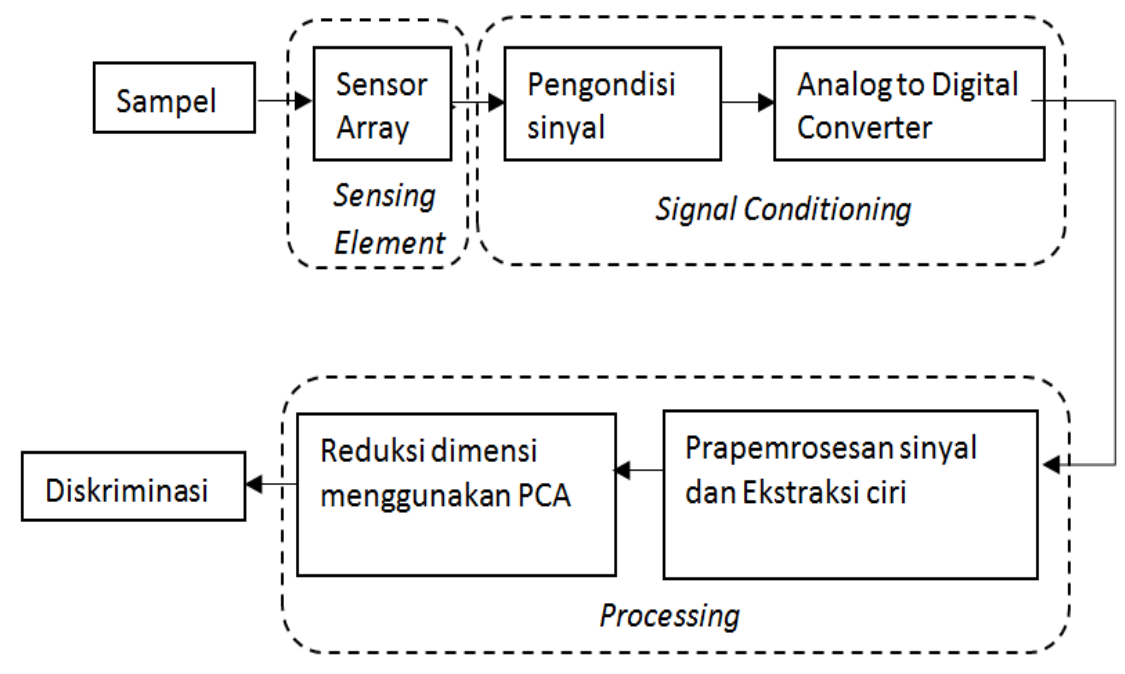

Gambar 1 Diagram blok sistem electronic nose

Perangkat keras e-nose yang digunakan pada penelitian ini mempunyai 4 bagian yang ditunjukkan pada Gambar 2. Penjelasan bagian-bagian perangkat keras e-nose adalah sebagai berikut

1. Bagian ruang sampel yaitu tempat tertutup yang berfungsi untuk meletakkan sampel yang akan diuji. Pada bagian ini terdapat pemanas yang berfungsi untuk memanaskan sampel saat dilakukan pengujian agar senyawa-senyawa volatile pada sampel lebih mudah menguap. Pemanas sampel dikendalikan dengan sistem kendali on-off dengan menggunakan relay sebagai aktuator switch untuk menghidupkan dan mematikan pemanas. Umpan balik data pembacaan suhu diperoleh dari sensor suhu LM35.

2. Bagian ruang sensor yaitu ruang tertutup dimana sensor array berada, bagian ruang sampel dan ruang sensor terhubung melalui ventilasi dengan kipas yang berfungsi untuk mengalirkan udara dari ruang sampel menuju ruang sensor saat dilakukannya pengujian sampel. Pada bagian ruang sensor terdapat dua kipas yang berfungsi untuk mengalirkan udara pada saat flushing yaitu proses pembersihan udara dalam ruang sensor dengan memasukkan udara bersih dari luar.

3. Bagian pengondisi sinyal dan konversi analog ke digital yang terdiri dari rangkaian elektronik pengondisi sinyal dan board mikrokontroler Arduino Mega 2560 dengan mikrokontroler ATMega 2560 di dalamnya yang berfungsi sebagai analog to digital converter dengan resolusi 10 bit.

4. Bagian unit pengolah data yaitu Personal Computer.

Respons dinamis sensor e-nose saat proses sensing dan flushing pada saat dilakukan pengujian sampel ditunjukkan pada Gambar 3. Proses sensing ditunjukkan pada bagian Odor ON sedangkan proses flushing ditunjukkan pada bagian Odor OFF. Satu kali siklus pengambilan data terdiri dari Odor ON (sensing) dan Odor OFF (flushing), Odor ON adalah respons sensor saat terpapar aroma sampel dan Odor OFF adalah respons sensor saat terpapar udara bersih. Bagian baseline menunjukkan respons sensor saat pembacaan data tanpa adanya sampel uji atau dengan kata lain baseline adalah nilai acuan hasil pembacaan sensor saat terpapar udara bersih. Respons transien sensor adalah respons keseluruhan sensor saat Odor ON dan Odor OFF. 


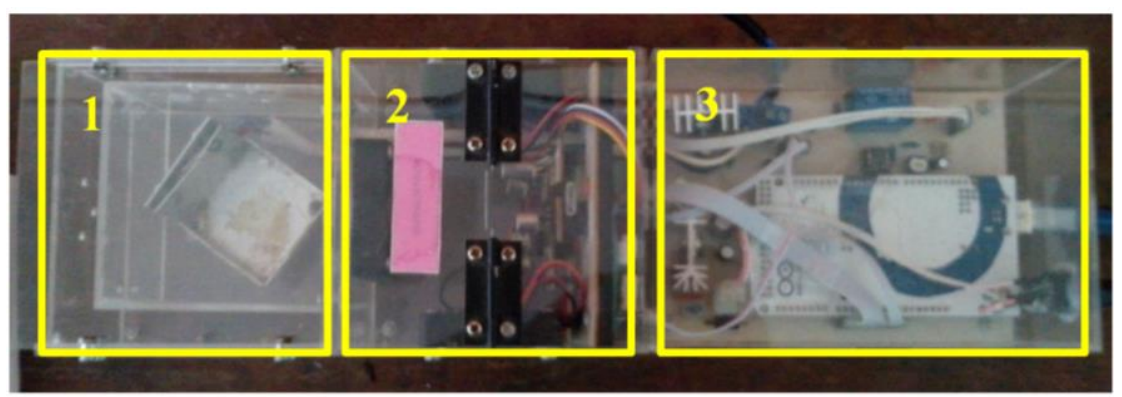

a

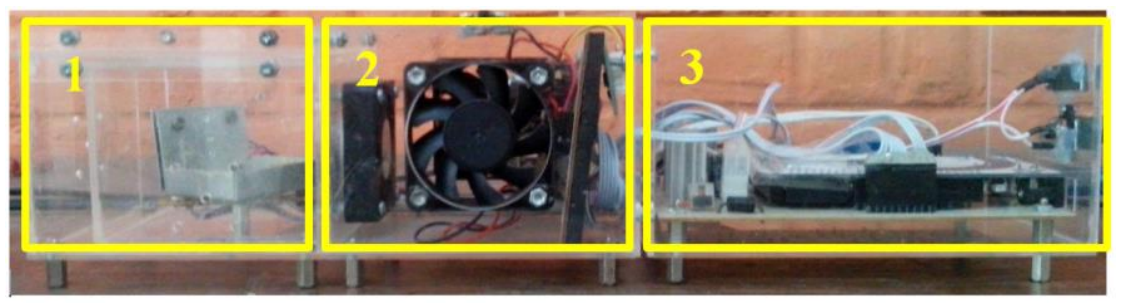

b

Gambar 2 Perangkat keras electronic nose (a) tampak atas dan (b) tampak samping

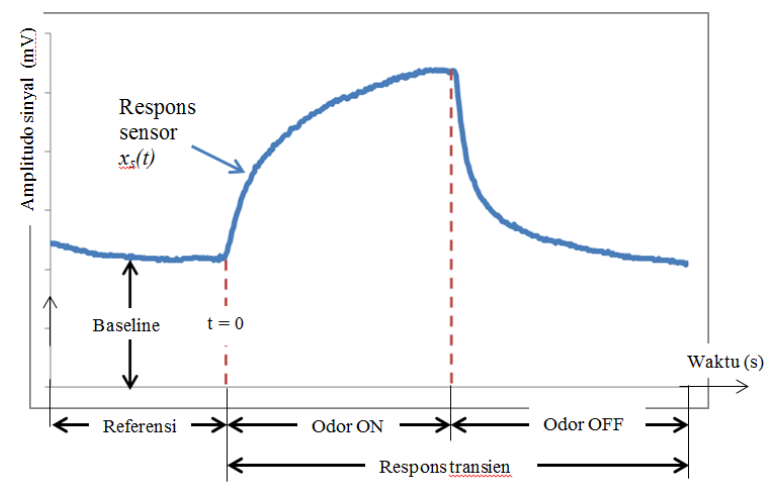

Gambar 3 Respons transien sensor pada electronic nose

\subsection{Prosedur dan Pengumpulan Data}

\subsubsection{Preparasi sampel}

Sampel yang digunakan pada penelitian ini adalah daging sapi segar dan daging babi segar. Preparasi sampel dilakukan dengan membuat 6 jenis sampel daging cincang yaitu sampel daging sapi murni, sampel daging babi murni, dan 4 jenis sampel daging cincang campuran yaitu daging sapi yang dicampur dengan daging babi dengan perbandingan tertentu. Masingmasing sampel daging mempunyai massa 20 gram. Sampel daging campuran dibuat dengan persentase kandungan daging babi $20 \%, 40 \%, 60 \%$, dan $80 \%$. Sampel daging segar dibeli pada pagi hari dimana daging berasal dari hewan yang disembelih pada hari yang sama saat daging dibeli.

\subsubsection{Pengumpulan data}

Tahap-tahap pengujian sampel untuk proses pengambilan data adalah sebagai berikut

1. Pada awal penggunaan, Electronic nose dinyalakan kemudian dilakukan proses flushing selama 10 menit untuk menstabilkan respons sensor-sensor e-nose terhadap udara bersih.

2. Sampel uji ditempatkan pada wadah yang terbuat dari alumunium foil, kemudian sampel diletakkan di dalam ruang sampel diatas pemanas. Selama proses pengambilan data, sampel dipanaskan pada suhu $50^{\circ} \mathrm{C}$ (nilai setpoint suhu pemanas) dengan tujuan agar senyawa volatile pada daging dapat lebih mudah menguap. 
3. Dilakukan pengambilan data dengan laju sampling data 1 detik untuk setiap data. Siklus proses sensing dan flushing dilakukan bergantian secara kontinu dengan durasi sensing dilakukan selama 3 menit dan durasi flushing selama 3 menit sehingga satu kali siklus sensing-flushing membutuhkan waktu 6 menit. Proses pengambilan data masing-masing sampel dilakukan sebanyak 7 kali siklus flushing-sensing sehingga total waktu pengambilan data untuk tiap sampel adalah 42 menit, dengan demikian didapatkan 2520 data untuk masing-masing sensor.

Diagram alir proses pengambilan data sampel dengan menggunakan e-nose ditunjukkan pada Gambar 4.

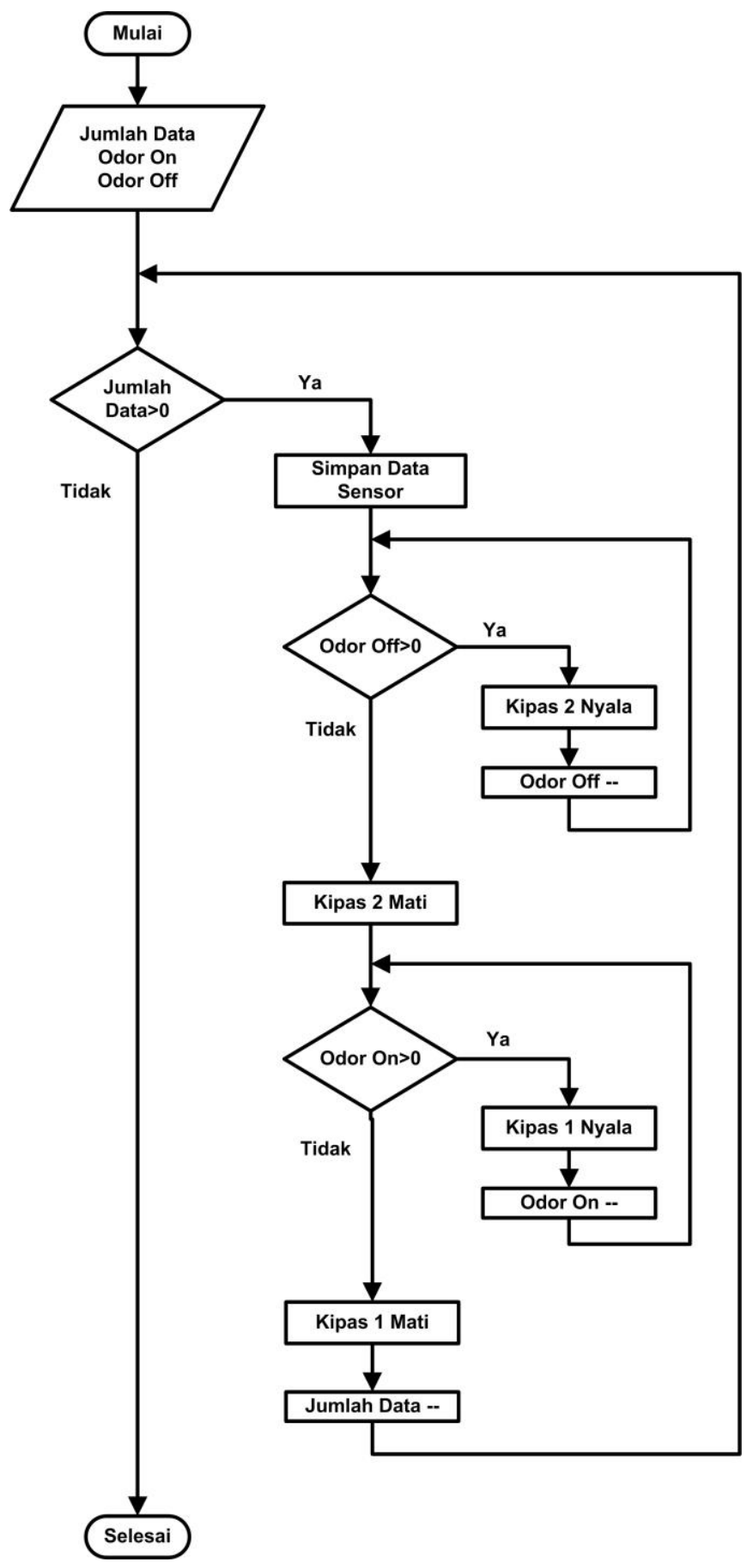

Gambar 4 Diagram alir pengambilan data menggunakan e-nose 


\subsubsection{Pengolahan dan analisis data}

Data hasil pengujian sampel menggunakan e-nose kemudian diolah menggunakan perangkat personal computer dimana data hasil pengujian sampel adalah berupa nilai tegangan yang berasal dari luaran sensor-sensor e-nose, data tersebut tersimpan dalam bentuk tabel spreadsheet. Tahap-tahap pengolahan data adalah sebagai berikut:

1. Signal preprocessing yaitu proses untuk untuk mengembalikan sinyal respon sensor ke nilai baseline awal, karena setelah pembersihan sensor, nilai baseline mengalami pergeseran dan sulit untuk dapat tepat kembali ke titik baseline semula. Signal preprocessing dilakukan dengan menggunakan metode manipulasi baseline diferensial dengan persamaan (1) [4]

$$
y_{s}(\mathrm{t})=\left(x_{s}(\mathrm{t})+\delta_{A}\right)-\left(x_{S}(0)+\delta_{A}\right)=x_{S}(\mathrm{t})-x_{S}(0)
$$

2. Ekstraksi ciri (feature extraction) yaitu proses untuk mengekstraksi nilai yang paling relevan dan informatif yang dapat mewakili ciri respons sensor secara keseluruhan. Ekstraksi ciri dilakukan dengan menghitung luasan kurva sinyal respons sensor pada bagian rise (Odor $O N$ ) dan pada bagian recovery (Odor $O F F$ ) pada satu kali siklus Odor ON-Odor OFF dengan menggunakan pendekatan aturan integral atau integral numeris dengan aturan trapesium (trapezoid rule) dengan persamaan (2) [5].

$$
\int_{a}^{b} f(x) d x \approx T n=\frac{\Delta x}{2}\left[f\left(x_{0}\right)+2 f\left(x_{1}\right)+2 f\left(x_{2}\right)+\cdots+2 f\left(x_{n-1}\right)+f\left(x_{n}\right)\right]
$$

3. Representasi data hasil pengujian dalam bentuk grafik radar (radar chart) yang menampilkan grafik berbentuk menyerupai jaring laba-laba yang berfungsi untuk menampilkan data yang berasal dari 5 sensor pada e-nose, representasi data menggunakan grafik radar dapat menampilkan perbedaan bentuk jaring antara satu sampel dengan sampel lainnya. Grafik radar diperoleh dari nilai rata-rata hasil ekstraksi ciri.

4. Analisis data menggunakan Principal Component Analysis (PCA) untuk mereduksi dimensi data dengan cara mereduksi jumlah variabel, kemudian didapatkan nilai variansi masing-masing principal component.

5. Representasi data dengan menggunakan grafik score plot principal component dari nilai principal component pertama dan principal component kedua, grafik score plot dijadikan sebagai hasil akhir klasifikasi.

\section{HASIL DAN PEMBAHASAN}

\subsection{Uji Respons Sensor E-nose terhadap Sampel Daging Sapi, Daging Babi, dan Daging Campuran}

Uji respons sensor bertujuan untuk mengetahui nilai respons sensor e-nose saat pengujian sampel. Sensor-sensor e-nose memiliki respons (amplitudo sinyal) yang lebih besar terhadap suatu sampel dengan aroma yang lebih kuat atau terhadap senyawa gas dengan konsentrasi yang lebih tinggi, dibandingkan dengan sampel atau senyawa dengan aroma lemah atau terhadap konsentrasi senyawa gas rendah. Pada Gambar 5 dan Gambar 6 secara berturutturut ditunjukkan grafik respons sensor terhadap sampel daging murni dan daging campuran.

Berdasarkan grafik respons sensor yang ditunjukkan pada Gambar 5 dapat dilihat bahwa sinyal respons sensor e-nose pada pengujian daging babi mempunyai nilai respons (amplitudo) yang lebih besar dibandingkan dengan sinyal respons pada pengujian daging sapi, hal ini menunjukkan bahwa sampel daging babi memiliki karakter aroma yang lebih kuat dibandingkan dengan daging sapi, dapat diamati pula bahwa sinyal respons sampel daging babi naik lebih cepat dibandingkan dengan dengan sinyal respons sampel daging sapi, hal ini menandakan bahwa sensor e-nose lebih peka terhadap senyawa volatil daging babi dibandingkan dengan senyawa volatil daging sapi. Selanjutnya berdasarkan Gambar 6 dapat

IJEIS Vol. 6, No. 1, April 2016: $47-58$ 
diamati bahwa sinyal respons sensor e-nose menunjukkan nilai respons yang semakin tinggi seiring dengan meningkatnya kandungan daging babi pada daging sapi campuran. Berdasarkan hasil pengamatan respons sensor e-nose pada pengujian sampel dapat disimpulkan bahwa enose menghasilkan karakteristik sinyal respons yang berbeda-beda pada setiap jenis sampel daging babi, daging sapi, dan daging sapi campuran.

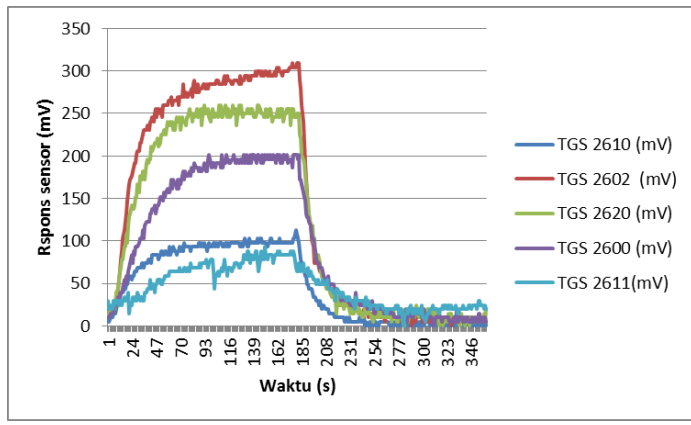

a

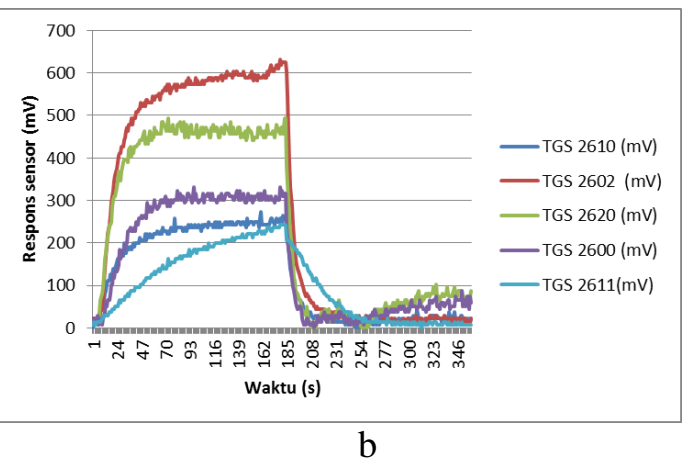

an (b) daging babi

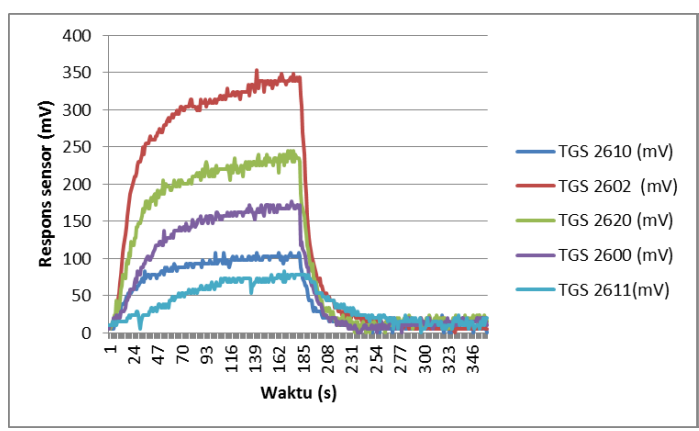

a

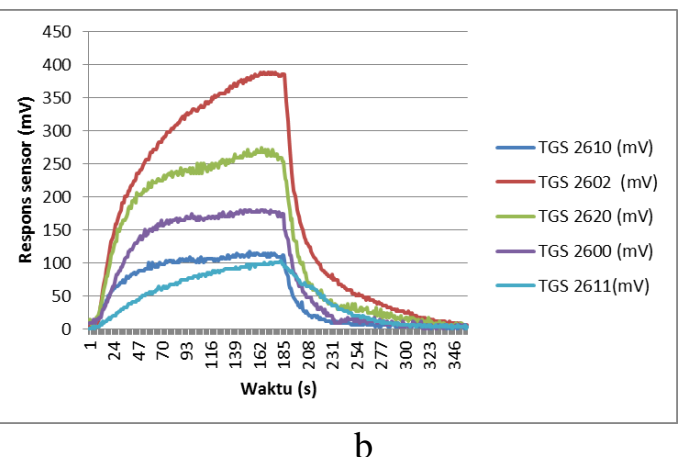

b

Gambar 6 Grafik respons e-nose terhadap sampel daging campuran dengan kandungan daging babi (a) $20 \%$, (b) $40 \%$, (c) $60 \%$, dan (d) $80 \%$

\subsection{Analisis Klasifikasi Daging Murni dan Daging Campuran}

Ekstraksi ciri data e-nose untuk sampel daging murni dan daging campuran menghasilkan data yang siap digunakan untuk pengolahan dan analisis lebih lanjut. Analisis tahap awal dilakukan dengan membuat visualisasi data menggunakan grafik radar berdasarkan nilai rata-rata hasil ekstraksi ciri untuk melihat perbedaan pola yang dihasilkan e-nose terhadap sampel. Gambar 7 dan Gambar 8 secara berturut-turut menunjukkan grafik radar untuk sampel daging murni dan sampel daging campuran.

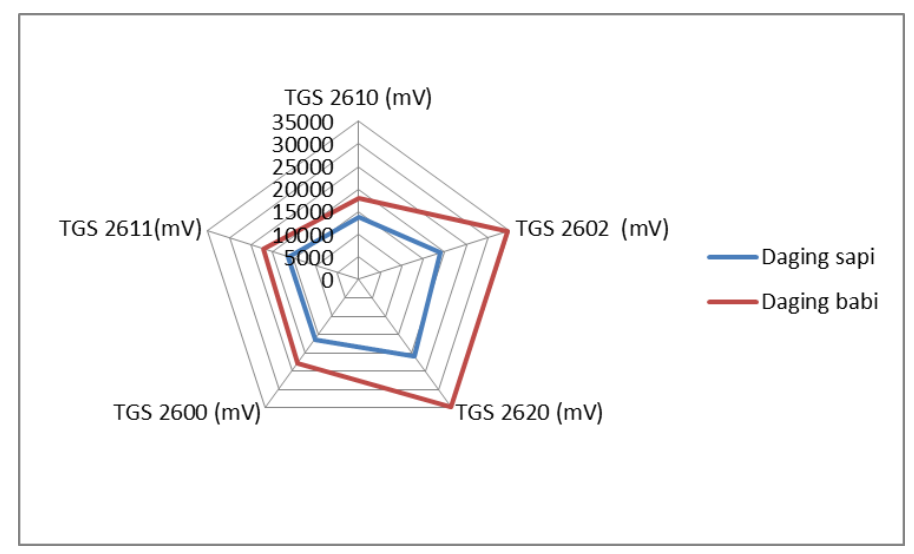

Gambar 7 Pola grafik radar data e-nose pada pengujian sampel daging murni 


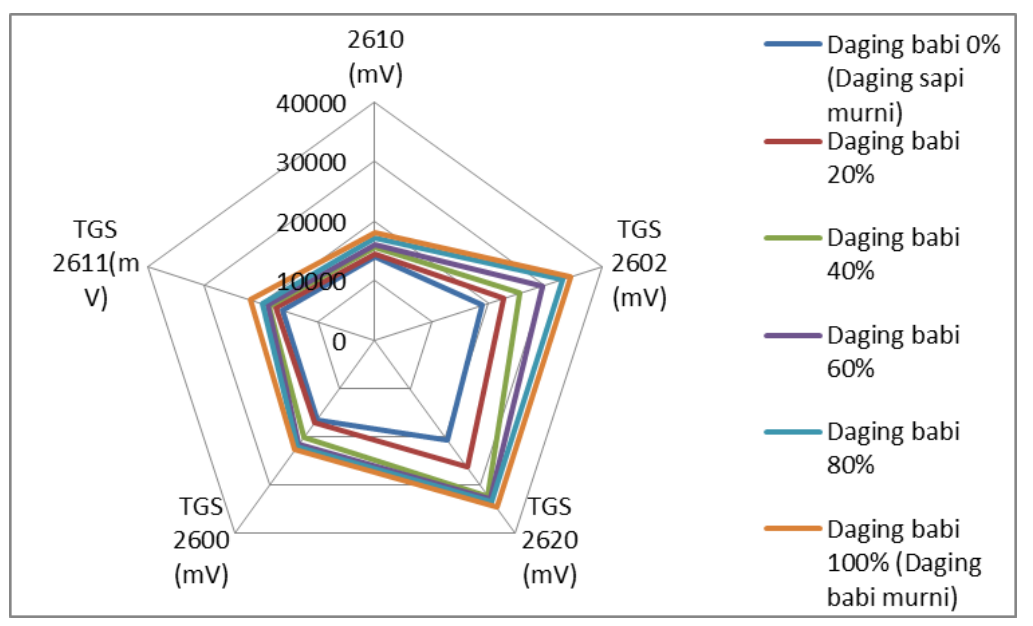

Gambar 8 Pola grafik radar data e-nose pada pengujian daging campuran

Berdasarkan Gambar 7 dapat diketahui bahwa e-nose menghasilkan pola respons sensor yang berbeda pada pengujian dua jenis sampel daging murni yaitu daging sapi dan daging babi di mana seluruh sensor e-nose menghasilkan nilai respons yang lebih tinggi pada pengujian daging babi dibandingkan pada pengujian daging sapi sehingga pola grafik radar yang dihasilkan untuk daging babi menunjukkan area grafik yang lebih luas dibandingkan area grafik untuk daging sapi. Pada Gambar 8 dapat dilihat bahwa e-nose menghasilkan pola respons sensor yang berbeda pada setiap jenis daging campuran di mana seluruh sensor e-nose menghasilkan nilai respons yang lebih tinggi seiring dengan meningkatnya kandungan daging babi pada daging campuran sehingga dihasilkan pola grafik radar yang menunjukkan perubahan yaitu menjadi semakin luas seiring dengan bertambahnya kandungan daging babi pada sampel daging campuran. Berdasarkan kedua Gambar tersebut dapat diketahui bahwa e-nose mampu menghasilkan karakteristik pola yang berbeda untuk sampel daging murni dan sampel daging campuran, dengan demikian dapat dilakukan analisis lebih lanjut untuk mendapatkan hasil yang lebih informatif untuk analisis klasifikasi sampel.

\subsection{Analisis Klasifikasi Daging Murni dan Daging Campuran dengan Principal Component Analysis}

Analisis data dengan menggunakan metode principal component analysis (PCA) bertujuan untuk mereduksi dimensi variabel yang saling berkorelasi menjadi variabel tereduksi yang tak berkorelasi secara linier yang disebut sebagai principle component (komponen utama) untuk menjelaskan semaksimal mungkin variansi yang terjadi dengan seminimal mungkin jumlah komponen utama. Jumlah variabel masukan pada proses PCA adalah 5 variabel yang mewakili jumlah sensor pada e-nose, variabel ini pada akhirnya akan direduksi menjadi dua dimensi yang terdiri dari komponen utama pertama (PC1) dan komponen utama kedua (PC2) yang dapat mewakili persentase nilai variansi yang signifikan dari total keseluruhan variansi data yang terjadi dan digunakan untuk membuat grafik visualisasi data dua dimensi untuk analisis dan interpretasi informasi secara kualitatif. Gambar 9 merupakan hasil score plot dua dimensi pada dua komponen utama pertama untuk data pengujian sampel daging murni.

Dua komponen utama pertama pada grafik score plot Gambar 9 mampu menjelaskan persentase variansi 99,9\% dari total variansi data keseluruhan dengan masing-masing persentase variansi sebesar 98,6\% untuk PC1 dan 1,3\% untuk PC2. Pada Gambar tersebut dapat dilihat bahwa kumpulan (cluster) titik-titik data untuk sampel daging sapi dapat terpisah dengan kumpulan titik-titik data untuk sampel daging babi. Hal ini menunjukkan bahwa enose mampu membedakan sampel daging sapi murni segar dengan daging babi murni segar berdasarkan karakteristik aroma sampel tersebut.

IJEIS Vol. 6, No. 1, April 2016 : 47 - 58 


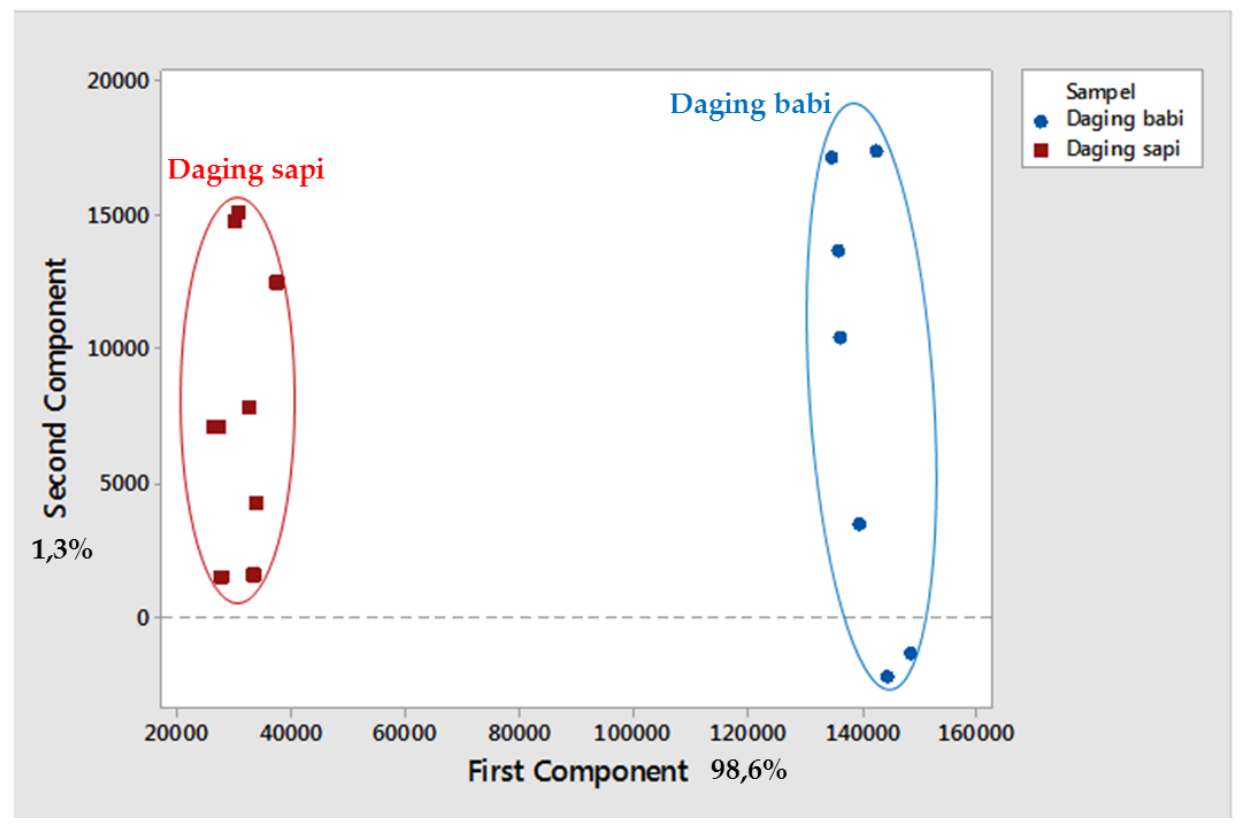

Gambar 9 Grafik score plot PCA untuk sampel daging murni

Pada pengujian daging campuran dilakukan dilakukan analisis untuk mengetahui apakah e-nose mampu membedakan sampel daging murni dengan sampel daging campuran. Hasil score plot PC1 dan PC2 untuk sampel daging campuran ditunjukkan pada Gambar 10.

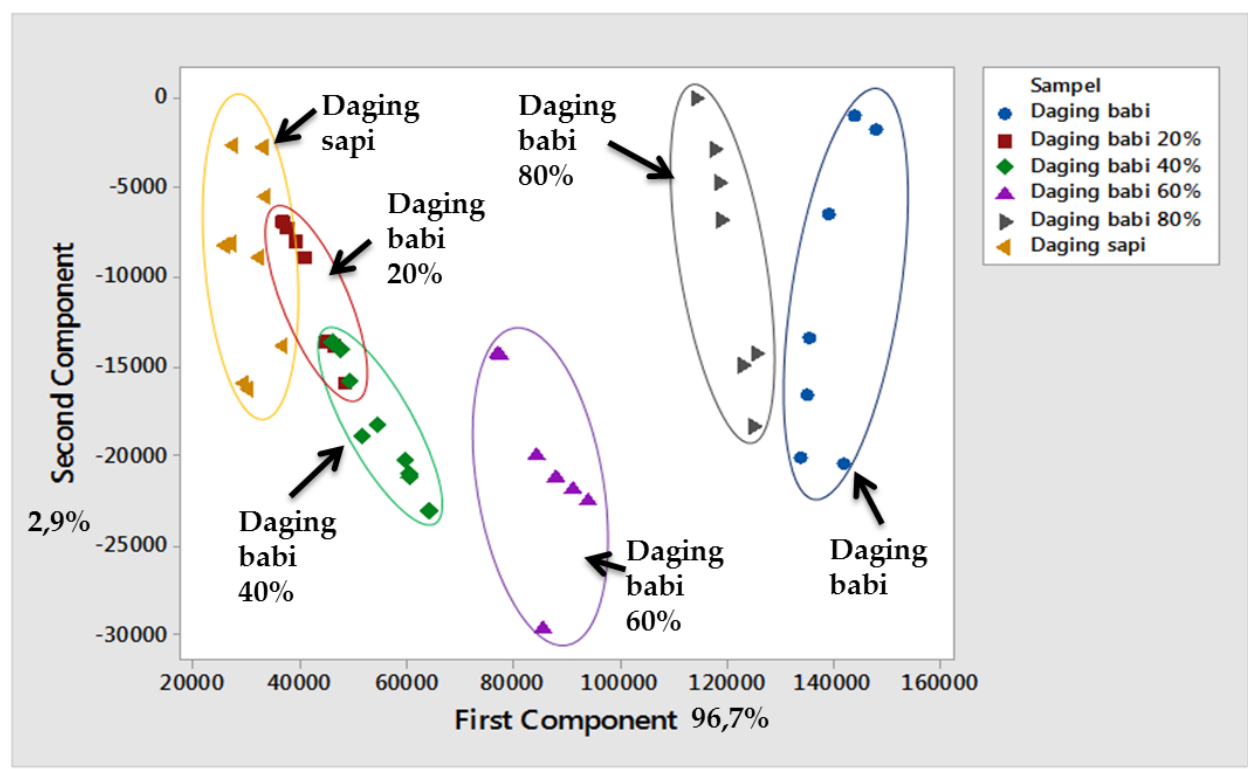

Gambar 10 Grafik score plot PCA untuk sampel daging murni dan daging campuran

Dua komponen pertama PC1 dan PC2 pada dalam merepresentasikan data secara visual melalui score plot mampu menjelaskan persentase variansi data sebesar 99,6\% dari total variansi data keseluruhan dengan persentase variansi komponen utama pertama dan kedua secara berturut-turut yaitu $96,7 \%$ dan 2,9\%. Pada grafik tersebut dapat diamati bahwa kumpulan (cluster) titik-titik data pada masing-masing jenis sampel dapat terpisah satu sama lain meskipun terdapat cluster yang saling bertumpang tindih sebagian yaitu pada cluster sampel daging babi murni, daging babi $20 \%$, dan daging babi $40 \%$. Berdasarkan pengamatan pada 
grafik Gambar 10 dapat diketahui bahwa e-nose mampu membedakan sampel daging campuran sapi dengan babi berdasarkan karakteristik aroma sampel tersebut.

\subsection{Analisis Sampel Pasar}

Pada penelitian ini dilakukan pengujian sampel daging sapi segar yang diperoleh dari 4 lokasi pasar berlainan yang dipilih secara acak untuk mengetahui dan membandingkan data hasil pengujian sampel pasar dengan data hasil pengujian sampel daging campuran. Data hasil pengujian 4 sampel pasar ditunjukkan melalui grafik radar dan grafik score plot PCA secara berturut turut pada Gambar 11 dan Gambar 12 .

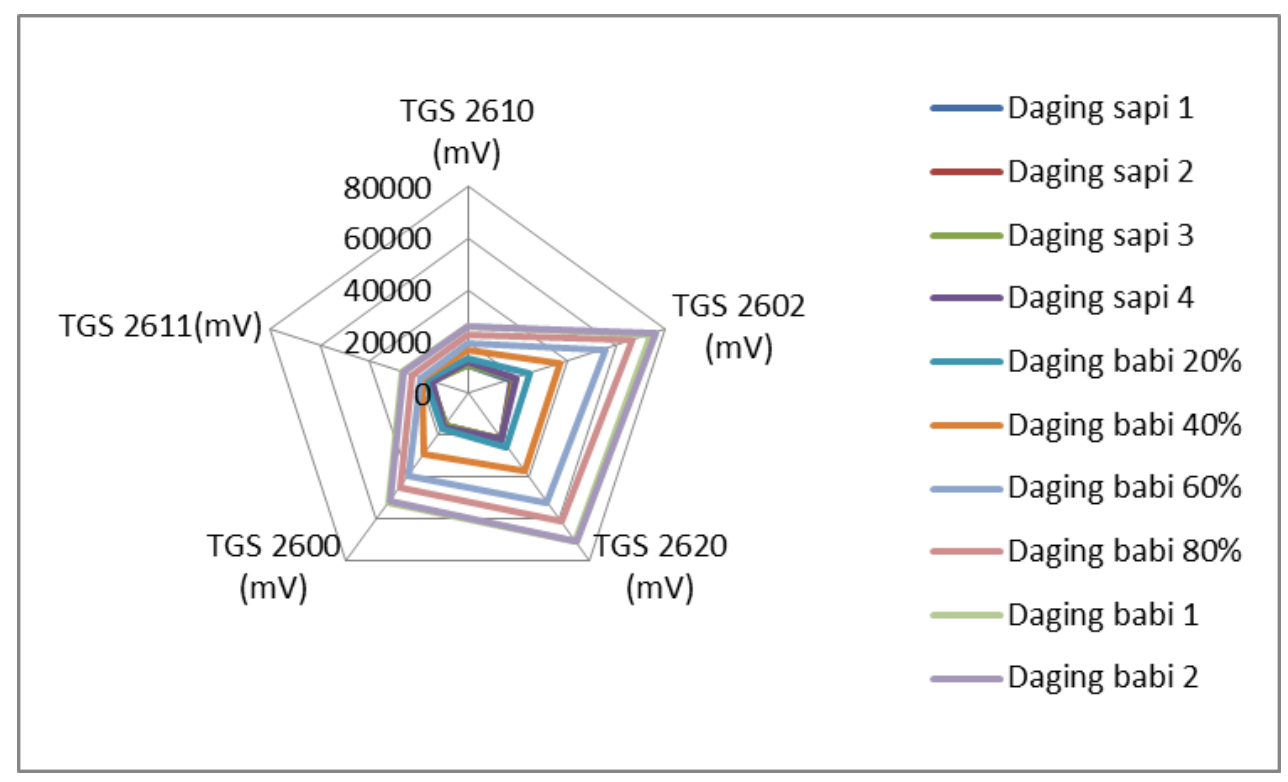

Gambar 11 Pola grafik radar klasifikasi seluruh jenis sampel

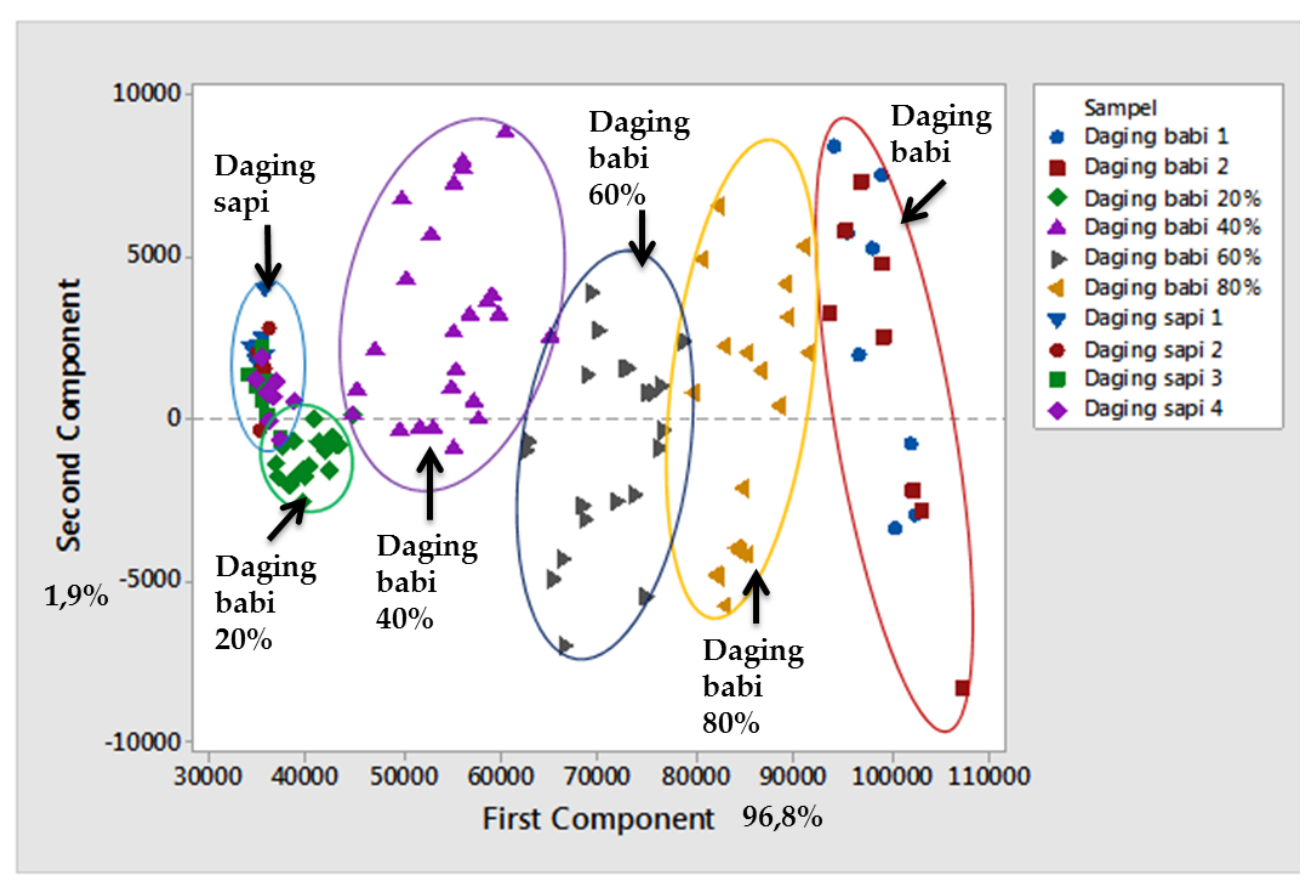

Gambar 12 Grafik score plot PCA klasifikasi seluruh jenis sampel 
Berdasarkan Gambar 11 dapat diamati bahwa sampel daging sapi segar yang berasal dari 4 pasar berbeda menunjukkan kesamaan pola grafik, dan jika dibandingkan dengan sampel daging campuran dan daging babi segar murni maka pola sampel daging sapi dari 4 pasar mempunyai area grafik yang lebih kecil. Pada grafik score plot PCA Gambar 12 dapat dilihat bahwa sampel daging sapi segar dari 4 pasar yang berbeda membentuk cluster sendiri yang terpisah dengan jenis sampel daging campuran dan daging babi, dengan persentase variansi untuk komponen utama pertama dan komponen utama kedua secara berturut-turut sebesar 96,8\% dan 1,9\% sehingga menghasilkan persentase variansi total sebesar 98,7\% Dari hasil pengujian 4 sampel pasar yang berbeda tersebut dapat diketahui bahwa e-nose mampu membedakan daging sapi murni dengan daging babi dan membedakan daging sapi murni dengan daging campuran sapi dan babi.

\section{KESIMPULAN}

Berdasarkan penelitian yang telah dilakukan maka dapat diambil kesimpulan sebagai berikut

1. E-nose berbasis larik 5 sensor gas metal oxide TGS 2600, TGS 2602, TGS 2610, TGS2611, dan TGS 2620 dapat membedakan antara sampel daging sapi murni dengan daging sapi campuran.

2. Analisis data menggunakan PCA untuk pengujian klasifikasi daging sapi dengan daging babi menghasilkan persentase variansi data sebesar $99,9 \%$ dan untuk pengujian klasifikasi daging sapi murni dengan daging sapi campuran sebesar 99,6\%.

\section{SARAN}

Saran yang disampaikan penulis untuk pengembangan penelitian yang akan datang adalah sebagai berikut

1. Dilakukan analisis data lebih lanjut yang melibatkan algoritma machine learning agar e-nose mampu menghasilkan hasil analisis yang lebih baik.

2. Dilakukan analisis data dengan beberapa metode dan dilakukan perbandingan untuk mengetahui metode yang paling efektif untuk analisis data pada e-nose.

3. Dilakukan pengujian dengan sampel dan variasi sampel yang lebih banyak untuk mengetahui potensi penggunaan e-nose yang lebih luas.

\section{DAFTAR PUSTAKA}

[1] Tian, X., Wang, J. dan Cui, S., 2013, Analysis of Pork Adulteration in Minced Mutton using Electronic Nose of Metal Oxide Sensors, Journal of Food Engineering, 119, 744749.

[2] Nurjuliana, M., Man Che, Y.B., Mat Hashim, D. dan Mohamed, A.K.S., 2010, Rapid Identification of Pork for Halal Authentication using Electronic Nose and Gas Chromatohraphy Mass Spectrometer with Headspace Analyzer, Meat Science, 638-644.

[3] Iswanto, W., 2014, Implementasi Rancang Bangun Electronic Nose untuk Mengklasifikasikan Pola Bau Tahu Murni dan Tahu Berformalin, Skripsi, Program Studi 
Elektronika dan Instrumentasi, Jurusan Ilmu Komputer dan Elektronika, Fakultas Matematika dan Ilmu Pengetahuan Alam, Universitas Gadjah Mada, Yogyakarta.

[4] Gutierrez-Osuna, R., Nagle, H.T., Kermani, B. dan Schiffman, S.S., 2003, Signal Conditioning and Preprocessing, Pearce, T.C., Schiffman, S.S., Nagle, H.T., dan Gardner, J.W., Handbook of Machine Olfaction: Electronic Nose Technology, WILEY-VCH, Weinheim.

[5] Distante, C., Leo, M., Siciliano, P. dan Persaud, K.C., 2002, On the Study of Feature Extraction Method for an Electronic Nose, Sensors and Actuators, B 87, 274-288. 